\title{
Co -occurring Mental Disorders among In-patients in a Substance use Disorder Treatment Center in Plateau State, Nigeria
}

\author{
Makput DM \\ Jos University Teaching Hospital, Jos \& Centre for Addiction treatment and Research Vom, Plateau state, Nigeria
}

*Corresponding Author: Dr Duwap. M.Makput, Department of Psychiatry, Jos University Teaching Hospital. PMB 2076, Jos, Plateau State,

Nigeria. Email: harrymakput@yahoo.co.uk

\begin{abstract}
Patients with psychoactive substance use disorders (SUD) often have co- occurring medical and mental disorders. This occurs as a result of a number of factors, for instance, drug abuse may facilitate the full expression of a latent psychiatric disorder; mental disorder may lead to SUD (drugs used for self- medication; or both SUD and mental disorders are caused by the same underlying brain deficit such as a genetic vulnerability, neurotransmitter abnormality, structural or functional abnormality, and so on. After obtaining ethical clearance, the case notes of all patients who were admitted in the Centre for Addiction Treatment and Research, (CATR) Vom, Plateau state throughout the first quarter of year 2019 were traced. A systematic random sample of every third consecutive patient was selected beginning with the first patient admitted and relevant data were collected and analyzed. A total of fourty- eight (48) in-patients were analyzed. Ninety -four percent (94\%) of the patients were males, a mean age of $23.6+5$ years with $46 \%$ being below 25 years of age. Fourty-six percent (46\%) had cannabis as their primary drug followed by alcohol (32\%) and opioids (28\%). Only $1 \%$ had a history of injecting drug use. Twenty nine percent (29\%) of the SUD patients had co-occurring depression, nine percent $(8 \%)$ had anxiety disorder, and five percent (4\%) had Post Traumatic Stress Disorder (PTSD) in addition to their substance use disorder. In line with sustainable development goals (SDG) goal 3.5 which seeks to "strengthen prevention and treatment of substance abuse including narcotics drug abuse and harmful use of alcohol"; identifying co-occurring mental disorders among patients with substance use disorders is one way of moving closer towards achieving this SDG.
\end{abstract}

Keywords:Co-occurring, Mentaldisorders, Patients, Substance use disorder.

\section{INTRODUCTION}

A diagnosis of a co-occurring disorder is made when at least one mental or medical disorder can be established in addition to and independent of the substance use disorder. ${ }^{1}$ Other terms that have been used to describe this phenomenon especially in the past are "mentally ill chemical abuser; chemically addicted and mentally ill; dually disordered; comorbid disorders and dual diagnosis."
Historically, more than 25 years ago Woody and Blaine first drew attention to an emerging literature describing a relationship between mental health problems (depression) and substance use disorders among substance abuse treatment clients. In spite of those early findings, the effort to develop an effective response to mental health problems among this category of patients is a more recent phenomenon, due to increasing concern on 
co-occurring mental health problems among patients bn substance abuse treatment. ${ }^{2}$

Virtually since the introduction of community-based treatment, clinicians have been challenged by health and psychosocial problems additional to those of substance use disorders. Infectious disease and other problems have been cited as characterizing substance abuse treatment clients ${ }^{3}$

Nowadays, the health care providers are expected to treat more than the substance use problems and accompanying social problems that have been recognized. They are being pressured to identify and treat the multiple and co-occurring mental disorders seen as characterizing a substantial proportion of the clients entering their clinics. Whether these expectations are met directly through on-site services or through the establishment of linkages to the mental health services system depends, in large part, on organizational factors beyond the control of the individual counselor and sometimes beyond the control of the substance abuse treatment program. Whether resources permit the training and supervision of current staff; whether resources permit the hiring of specialized staff; whether that staff is available in a community; and whether mental health services are readily accessible in a community will all help to determine the response the substance abuse treatment program can make to the mental health needs of its clients and the treatment outcome in general.

The problem of co-occurring substance use and mental disorders (COD) is common. The largest study of cooccurring disorders to date, the National Epidemiologic Survey on Alcohol and Related Conditions (NESARC), found that approximately $20 \%$ of all persons in the general population with a current substance use disorder had at least one current independent (i.e., non-substance-induced) mood disorder, and $18 \%$ had at least one current independent anxiety disorder. ${ }^{4,5}$

Individuals with COD tend to be worse off than those with substance use or mental disorders alone on a variety of dimensions ${ }^{6,7}$. Persons with COD have been found to suffer from hepatitis $\mathrm{C}^{8,9}$ high unemployment ${ }^{10}$, unstable housing ${ }^{11,12,}$ and a history of suicide attempts as a result of comorbid depression ${ }^{13}$.

\section{Prevalence of Co-occurring disorders in treatment populations.}

Reports from treatment programs of lifetime evidence of cooccurring disorder have varied widely, but have generally involved high estimates of COD (Cacciola, Alterman, McKay, \& Rutherford, 2001) $)^{14}$ findings are as summarized by Sacks \& Ries. These investigators describing substance abuse treatment client populations during the decades of the $1980 \mathrm{~s}$ and $1990 \mathrm{~s}$, have reported 50 to $70 \%$ of their clients showing lifetime histories of co-occurring disorders, while the same investigators, describing mental health treatment populations during the same period, have reported 20 to $50 \%$ of their clients showing lifetime histories of substance use disorders. ${ }^{14}$

Recent studies of treatment programs and clients have supported these earlier estimates. McGovern, Xie, Segal, Siembab, and Drake (2006) $)^{15}$ surveyed addiction treatment agency directors, clinical supervisors, and clinicians in a single state system about co-occurring disorders among their clientele. They found overall estimates of $41 \% \operatorname{mood}$ disorders, 26\% anxiety disorders, 25\% PTSD, 17\% severe mental illness, $18 \%$ antisocial personality disorder, and $17 \%$ borderline personality disorder. Watkins ${ }^{16}$ and colleagues screened admissions to three outpatient substance abuse treatment clinics and found that about 50\% had co-occurring mental health disorders.

In the African continent, the substance use disorder and mental health situation, just like other health indices are usually worse than in the developed world. For example, Substance use represents a major public health problem in South Africa. Results from the South African Stress and Health Study (SASH), the first nationally-representative study of psychiatric morbidity in South Africa indicate a high lifetime prevalence (13.3\%) and early onset (21 years) of substance use disorders. ${ }^{17}$ Despite this high prevalence, only $27.6 \%$ of South Africans who met the criteria for a substance use disorder received treatment in the year preceding the interview. ${ }^{18}$

Only a few studies on co-morbidity in Nigeria have been carried out, for example, Adewuya ${ }^{19}$ in a school based study in south western Nigeria reported a comorbidity rate of alcohol dependence with adolescent depression to be $23.8 \%$; Abdulmalik $^{20}$ studied comorbidity of depression with substance use among high school students in Maiduguri, north eastern Nigeria and found that $50 \%$ of the students who used psychoactive substances had co morbid depression. These studies were school based, none addressed the issue of co-occurring mental illness among people who are in treatment for substance use disorders.

There is a paucity of studies on co-occurring mental illnesses 
among patients with psychoactive substance use disorders in Nigeria especially in the north central parts of the country. Moreover, the sustainable development goal 3.5 which seeks to "strengthen prevention and treatment of substance abuse including narcotic drug abuse and harmful use of alcohol"underscores the need for this study. A better understanding of Co-occurring SUD and mental disorders will lead to improved treatment outcome and better health which in turn leads us closer to achieving SDG 3

\section{MATERIALS AND METHODS}

\section{Study Location}

The Centre for Addiction treatment \& Research (CATR) Vom, Plateau state Nigeria, owned by Church of Christ In Nations (COCIN) which has a collaboration with Jos University Teaching Hospital (JUTH). The centre, being owned by COCIN church, is located within the premises of the popular Vom Christian Hospital, about $30 \mathrm{~km}$ south of the city of Jos in Plateau state. Vom Christian Hospital was established by the missionaries since 1922 and has since its establishment continued to offer a wide range of medical services to the general populace. The centre for addiction treatment is one of its recent additions to the range of services offered by this historic hospital.

\section{Study setting}

This was a hospital-based study.

\section{Study design.}

This is a cross sectional descriptive study. The inclusion criterion is all the patients that were on admission during the study period, the first quarter of year 2019i.e from January $1^{\text {st }}$ to March $31^{\text {st }}$. Because rehabilitation is usually a long stay ward, many of the patients on the admission list as at January $1^{\text {st }}$ were admitted since the preceding year and were included in the study. The patient with the earliest date of admission was considered as the first patient.

\section{Sampling technique}

A systematic random sample of every third consecutive patient was taken beginning with the first patient until all the patients within the sampling frame were exhausted

\section{Data collection and procedure.}

The case notes of all patients selected for the study were traced. Data collection was done in June 2019 wherein most of the patients who formed the sample for the study have been discharged. A socio-demographic questionnaire was used to collect relevant information relating to socio demographic data. All relevant clinical data and diagnosis of any mental

\section{Incidence of CODs}

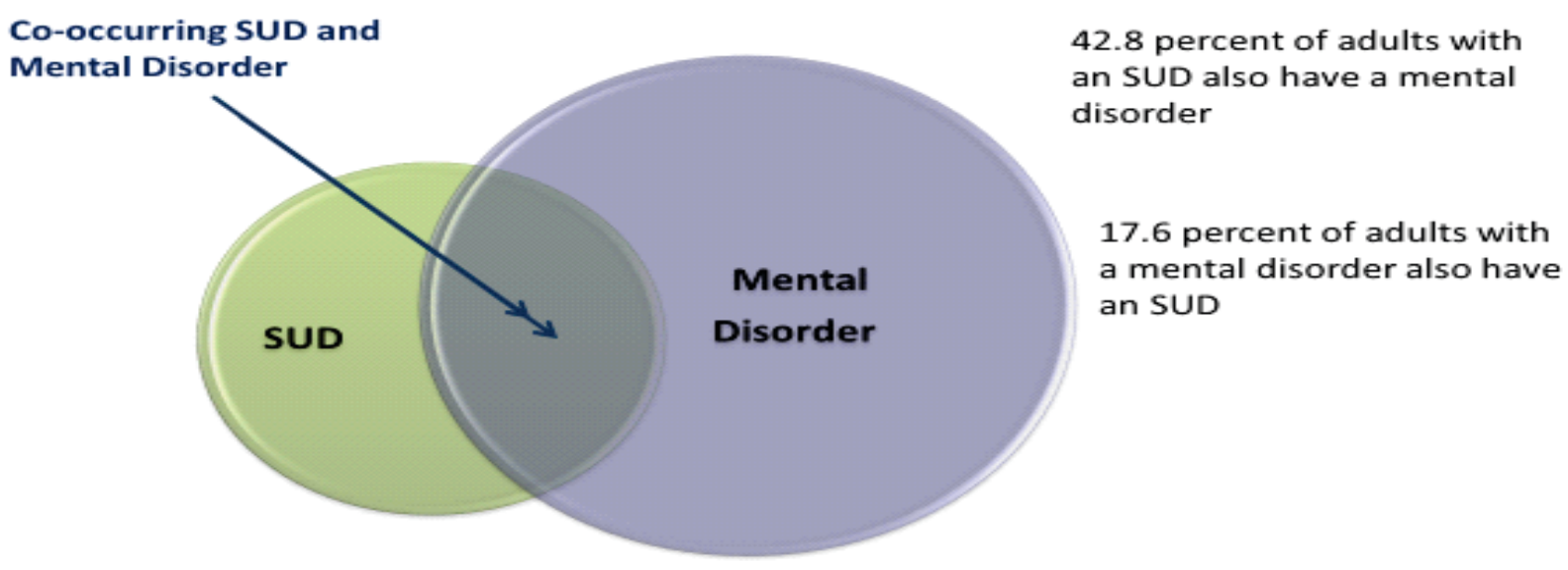

Source: U.S. Substance Abuse and Mental Health Services Administration. (2010). Resurts from the 2009 Nationol Survey an Drug Use and Hearth: Mental Hearth Findings, office of Applied Studies, NSDUH Series H-39, HHS Publication No. SMA 10-4609. Rockville, MD: U.S. Department of Health and Human Services.

Fig. 1. Diagram showing incidence of CODs 
illness found in the folders as made by the clinician were also collated as well as information on psychoactive substance use.

\section{Data analysis}

Data was cleaned and analyzed using SPSS version 21. Descriptive and analytical statistics were used to summarize data.

\section{Ethical consideration}

Ethical clearance was obtained from Centre for Addiction Treatment and Research (CATR) research ethics committee.

\section{RESULTS}

A total of 48 patients were selected for this study out of whom an overwhelming majority (94\%) was males with only $6 \%$ being females. They patients were predominantly young males. None of the patients was in their old age ( $>65$ years), the age range was 18 to 47 years with a mean age of $23.6 \pm 5$ years and $46 \%$ were either 25 years of age or younger.

Most of the patients were still single and have never married, a few were married $(8.3 \%$ ) and $12.5 \%$ were previously married which implies that they were either separated, divorced or widowed. Not surprisingly, majority of them $(77.1 \%)$ were unemployed with many still trying to complete their education at one stage or the other. However, all of them have completed at least primary education.

Concerning drug of abuse, $41 \%$ of them had cannabis as their primary drug defined as the drug causing the most problem by the United Nations office on Drug and crime (UNODC).

Table 1. socio demographic characteristics of the patients

\begin{tabular}{|c|c|c|}
\hline \multicolumn{3}{|l|}{ Age distribution } \\
\hline & 22 & 45.8 \\
\hline $25-34$ & 15 & 31.2 \\
\hline $35-44$ & 9 & 18.8 \\
\hline $45-54$ & 2 & 4.2 \\
\hline $55-64$ & O & $\mathrm{O}$ \\
\hline$>65$ & $\mathbf{O}$ & $\mathrm{O}$ \\
\hline Mean age & & \\
\hline \multicolumn{3}{|l|}{ Sex } \\
\hline Male & 45 & 93.7 \\
\hline Female & 3 & 6.3 \\
\hline \multicolumn{3}{|l|}{ Marital status } \\
\hline Never married & 38 & 79.2 \\
\hline Married & 4 & 8.3 \\
\hline Previously married & 6 & 12.5 \\
\hline \multicolumn{3}{|l|}{ Employment } \\
\hline Employed & 11 & 22.9 \\
\hline Unemployed & 37 & 77.1 \\
\hline \multicolumn{3}{|l|}{ Education } \\
\hline No formal education & O & O \\
\hline Completed primary & 5 & 70.3 \\
\hline Completed secondary & 34 & \\
\hline Tertiary & 9 & 18.8 \\
\hline
\end{tabular}

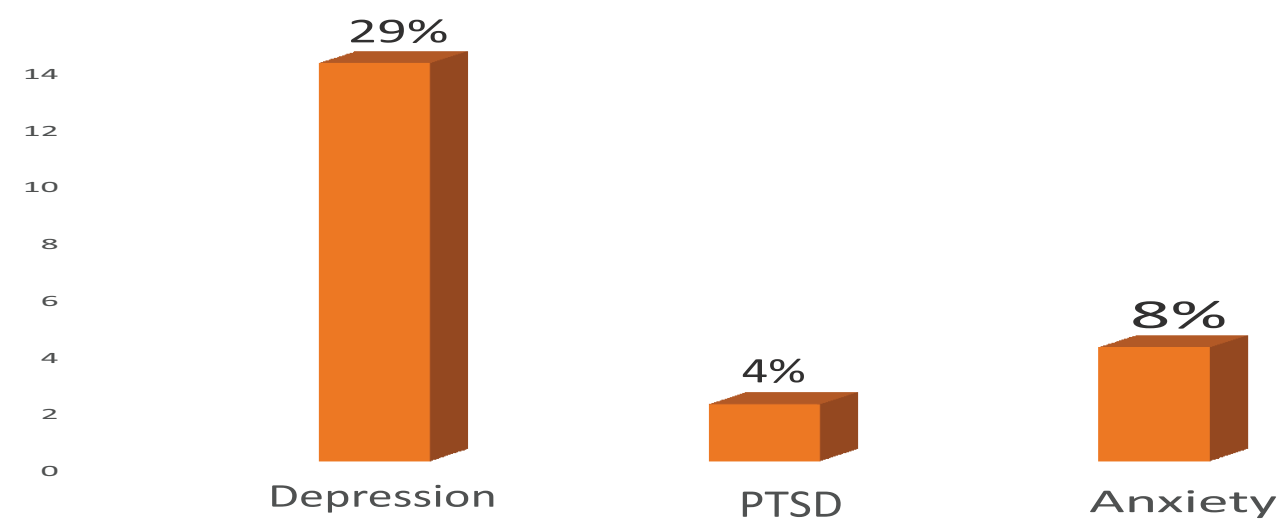

Fig.2. C-o occurring mental disorders in the patients 
Table 2. Relationship between Cooccurring depression and demographic variables.

\begin{tabular}{|c|c|c|c|c|c|c|}
\hline Variable & & & & & df & $p$-value \\
\hline Depression & & & & & & \\
\hline & Total & No & yes & & & \\
\hline Gender & & & & & & \\
\hline Male & $45(93.7 \%)$ & $33(18.8 \%)$ & $12(25.0 \%)$ & & 2 & 0.001 \\
\hline Female & $3(6.3 \%)$ & $1(2.1 \%)$ & $2(4.2 \%)$ & & & \\
\hline Total & $48(100 \%)$ & $34(70.8 \%)$ & $14(29.2 \%)$ & & & \\
\hline Age & & & & & & \\
\hline $16-24$ & $22(45.8 \%)$ & $16(33.3 \%)$ & $6(12.5 \%)$ & & 3 & 0.001 \\
\hline $25-34$ & $15(31.2 \%)$ & $10(20.8 \%)$ & $5(10.4 \%)$ & & & \\
\hline $35-44$ & $9(18.8 \%)$ & $7(14.6 \%)$ & $2(4.2 \%)$ & & & \\
\hline $45-54$ & $2(4.2 \%)$ & $1(2.1 \%)$ & $1(2.1 \%)$ & & & \\
\hline $55-64$ & $0(0 \%)$ & $0(0 \%)$ & $0(0 \%)$ & & & \\
\hline$>65$ & $0(0 \%)$ & $0(0 \%)$ & $0(0 \%)$ & & & \\
\hline Total & $48(100 \%)$ & $34(70.8 \%)$ & $14(29.2 \%)$ & & & \\
\hline Marital statu & & & & & & \\
\hline Never & $38(79.2 \%)$ & $29(60.4 \%)$ & $9(18.8 \%)$ & & 1 & 0.664 \\
\hline Married & $4(8.3 \%)$ & $3(6.3 \%)$ & $1(2.1 \%)$ & & & \\
\hline Previously & $6(12.5 \%)$ & $2(4.2 \%)$ & $4(8.3 \%)$ & & & \\
\hline Total & $48(100 \%)$ & $34(70.8 \%)$ & $14(29.2 \%)$ & & & \\
\hline Employment & & & & & & \\
\hline Employed & $11(23.9 \%)$ & $9(18.8 \%)$ & $2(4.2 \%)$ & & 2 & 0.001 \\
\hline Unemployed & $37(77.1 \%)$ & $25(52.1 \%)$ & $12(25.0 \%)$ & & & \\
\hline Total & $48(100 \%)$ & $34(70.8 \%)$ & $14(29.2 \%)$ & & & \\
\hline Education & & & & & & \\
\hline None & $0(0 \%)$ & $0(0 \%)$ & $0(0 \%)$ & 1 & & 163 \\
\hline Primary & $5(10.4 \%)$ & $4(8.3 \%)$ & $1(2.1 \%)$ & & & \\
\hline Secondary & $34(70.8 \%)$ & $23(47.9 \%)$ & $11(22.9 \%)$ & & & \\
\hline Tertiary & $9(18.8 \%)$ & $7(14.6 \%)$ & $2(4.2 \%)$ & & & \\
\hline Total & $48(100 \%)$ & $34(70.8 \%)$ & $14(29.2 \%)$ & & & \\
\hline
\end{tabular}

Thirty two percent had alcohol as their primary drug while $28 \%$ had an opioid as their primary drug. Only $1 \%$ had a history of injecting drug use mainly pentazocine. An overwhelming majority i.e $78 \%$ of them were abusing multiple drugs in various combinations ranging from opiates such as pentazocine, heroine, and codeine containing cough syrups, cannabis, CNS sedatives such as benzodiazepines, alcohol, barbiturates, CNS stimulants such as cigarette and cocaine, volatile solvents such as glue and petrol as well as a range of other local substances. In terms of the co-occurring mental disorders, the highest was depression recorded in $29 \%$ of the patients, $8 \%$ had co-occurring anxiety disorder whereas $4 \%$ has posttraumatic stress disorder (PTSD). Socio demographic factors significantly associated with the development of co-occurring depression were gender $(p$ $=0.001)$, age $(\mathrm{p}=0.001)$ and employment $(\mathrm{p}=0.001)$.

\section{DISCUSSION}

This study found a $29 \%$ rate of co-occurring depression among the patients with substance use disorder. This result is comparable to but slightly higher than $23.8 \%$ found by Adewuya ${ }^{19}$ in the south west but remarkably different from the $50 \%$ rate of depression among school children in the North east recorded by Abdulmalik. ${ }^{20}$ Perhaps, due to the insurgency going on in the area where Abdulmalik conducted his study, the extremely higher rate of depression may not be surprising considering the emotional turmoil they have been going through since the onset of insurgency over a decade ago. Another reason for the difference between our findings may be because these two studies (Adewuya 2006; Abdulmalik, 2013 ) were both school based studies whereas this was a hospital based study.

The implications of co-occurring mental disorders in 
people with substance use disorder are multifaceted. Cooccurring substance use disorders and mental illness increases the degree of morbidity, increases functional incapacity. It also increases mortality, prolongs duration of treatment, alter course of illness and outcome and may influence the type of care needed. ${ }^{21}$

\section{CONCLUSION}

Depression co-occurs commonly with substance use disorder at a rate of $29 \%$. It is followed by anxiety disorders $(8 \%)$ and post traumatic stress disorder PTSD at a rate of $4 \%$.

\section{Recommendations}

Due to the very frequent coexistence of substance use disorders and mental illnesses in the same individual, it is recommended as a routine to screen for possible co-occurring mental disorders when treating patients with substance use disorders. It is also a fact that in Nigeria, many "drug Rehabilitation and treatment centers" established by some Non- governmental organizations, some faith- based organizations and even some government parastatals such as NDLEA do not have Psychiatrists as part of their personnel. This scenario will invariably not allow the mental health needs of these patients to be adequately addressed. In the light of the findings of this and other studies, it is therefore recommended that such "treatment" centers should endeavor to include psychiatrists in their workforce in order to adequately take care of these frequently co-occurring mental disorders when treating patients with substance use disorder.

\section{Limitations}

This study was small in size and a retrospective, hospitalbased study. The data collected from the case notes relied only on the clinicians' notes. No instruments were administered to the patients.

\section{Acknowledgment}

The support and encouragement of the entire staff and management of CATR Vom is highly appreciated.

\section{Conflict of interest.}

None.

\section{REFERENCES}

1. The Universal treatment curriculum for substance use disorders (UTC). UNODC. Course 3. Common cooccurringmental and medical disorders- An overview for Addiction professionals. 2017. $3^{\text {rd }}$ edition. Pp. 79-82.

2. Henggeler SW, Halliday-Boykins CA, Cunningham PB, Randall J, Shapiro SB, Chapman JE. Juvenile drug court. Enhancing outcomes by integrating evidence based treatment. J Consult. Clin. Psych. 2006.74 (1):42-54.

3. McLellan AT, Carise D, Kleber HD . Can the national addiction treatment infrastructure support the public's demandfor quality care ? J substance abuse treatment. 2003.25(2): 117-121.

4. Grant BF, Stinson FS, Dawson DA, Chou P, Dufour MC, Compton W, et al. Prevalence and co-occurrence of substance use disorders and independent mood and anxiety disorders: Results from the National Epidemiologic Survey on Alcohol and Related Conditions. Arch Gen Psychiatry. 2004;61(8):807-816

5. Grant BF, Dawson DA. Introduction to the National Epidemiologic Survey on Alcohol and Related Conditions. Alcohol Res Health. 2006;29(2):74-78.

6. Kessler RC. Impact of substance abuse on the diagnosis, course, and treatment of mood disorders: The epidemiology of dual diagnosis. Biol Psychiatry. 2004;56(10):730-737.

7. O'Brien CP, Charney DS, Lewis L, Cornish JW, Post RM, Woody GE, et al. Priority actions to improve the care of persons with co-occurring substance abuse and other mental disorders: A call to action. Biol Psychiatry. 2004;56(10):703-713.

8. Dickey B, Normand S-LT, Weiss RD, Drake RE, Azeni H. Medical morbidity, mental illness, and substance use disorders. Psychiatr Serv. 2002;53(7):861-867.

9. Osher FC, Goldberg RW, McNary SW, Swartz MS, Essock SM, Butterfield MI, et al. Substance abuse and the transmission of Hepatitis $\mathrm{C}$ among persons with severe mental illness. Psychiatr Serv. 2003;54(6):842-847.

10. Watkins KE, Burnam A, Kung F-Y, Paddock S. A national survey of care for persons with co-occurring mental and substance use disorders. Psychiatr Serv. 2001;52(8):1062-1068.

11. Watkins KE, Hunter SB, Wenzel SL, Tu W, Paddock SM, Griffin A, et al. Prevalence and characteristics of Clients with co-occurring disorders in outpatient substance abuse 
treatment. The American Journal of Drug and Alcohol Abuse. 2004;30(4):749-764.

12. McNiel DE, Binder RL. Psychiatric emergency service use and homelessness, mental disorder, and violence. Psychiatr Serv. 2005;56(6):699-704.

13. Aharonovich E, Liu X, Nunes E, Hasin DS. Suicide attempts in substance abusers: Effects of major depression in relation to substance use disorders. The American Journal of Psychiatry. 2002;159(9):1600-1602 .

14. Cacciola JS, Alterman AI, McKay JR, Rutherford MJ. Psychiatric comorbidity in patients with substance use disorders: Do not forget axis II disorders. Psychiatric Annals. 2001;31:321-331.

15. McGovern MP, Xie H, Segal SR, Siembab L, Drake RE Addiction treatment services and co-occurring disorders: Prevalence estimates, treatment practices, and barriers. J Subst Abuse Treat. 2006; 31(3):267-75.

16. Watkins KE, Hunter SB, Wenzel SL, Tu W, Paddock SM, Griffin A, Ebener P. Prevalence and characteristics of clients with co-occurring disorders in outpatient substance abuse treatment. Am J Drug Alcohol Abuse. 2004;30(4):749-64.

17. Stein DJ, Seedat S, Herman A, Moomal H, Heeringa SG, Kessler RC. et al. Lifetime prevalence pf psychiatric disorders in South Africa. Br J Psychiatr. 2008;192:112-117.

18. Seedat S, Stein DJ, Herman A, Kessler R, Sonnega J, Heeringa S. et al.Twelve-month treatment of psychiatric disorders in the South African Stress and Health Study (World Mental Health Survey Initiative) Soc Psychiatry Psychiatr Epidemiol. 2008;43:889-897

19. Adewuya, AO. Prevalence of major depressive disorder in Nigerian college students with alcohol related problems. Gen Hosp Psychiatry 2006. 28(2): 169-173.

20. Abdulmalik JO, Omigbodun O, Wakil MA, Omeza B. Comorbidity of depression with substance use among high school students in northern Nigeria. 2013. https://www.academia.edu/1373226

21. Kang H-J, Kim S-Y, Bae K-Y, et al. Comorbidity of Depression with Physical Disorders: Research and Clinical Implications. Chonnam Med J. 2015;51(1):8-18. 